\title{
Are We There Yet? Assessing the Readiness of English Department, FKIP-Unpatti for E-Learning and Technology Enhanced Language Learning/Teaching
}

\author{
Helena M. A. Rijoly \\ English Department \\ Universitas Pattimura, Ambon, Maluku \\ rijolyhelena@yahoo.co.uk
}

\begin{abstract}
Every developed universities or even education institutes and agencies strive to tapped into digital/technology enhanced learning/teaching as a way to enriched and improve the quality of education as well as to reach out to the digital natives which are the students. The question remain to the readiness of those involve in the system. E-Learning framework and system are developed, adapted, installed and launched but more often it is focused on the development of the facilities, infrastructure and content. The most important aspects neglected are the users: students and lecturers. The readiness of the students and lecturers is crucial to ensure the outcome of the process. This study employs survey method with questionnaires as its main instrument to obtain and create baseline data of English Department, FKIP-Unpatti. The baseline data is divided into 4 data categories: 1) Demographic Data, 2) Habit and Preferences, 3) Resources and 4) Perceived level of Digital Literacy Skill. The survey will be conducted to students and lecturers of English Department, FKIP-Unpatti. The analysis of the result of the study aims to answer the main overarching question of how ready are the students of English Department, FKIP-Unpatti to embark on E-Learning and Technology Enhanced Language Learning/Teaching.
\end{abstract}

Keywords: E-Learning, Technology Enhanced Language Learning, Digital Literacy, Digital Readiness

\section{INTRODUCTION}

Technology, connectivity and digital/virtual gadgets and what-nots have become part of our daily need in parallel with rice and water for our life. Before our feet touch the floor in the morning we have that burning need to connect, to use some form of these technology outlets. Social media has become our second skin. Everything is provided for us at our finger tips.

The young generation we are teaching at the moments are called 'Digital Natives' (Prensky, 2001) where their brain is wired with the DNA suited for digital and technology based development. These new breed of generation develop due to the widespread development, accessibility and availability of technology and economic development. These generation is flooded with sensory stimulation technology and luxury of connectivity via technology (Robinson).

Sir Ken Robinson (2006) in one of his TEDTalks address the need for education system to keep up and adjust to these Digital Natives. It is a tragedy when these students have all the information channels around them and being bombarded with information (both good/useful and bad/destructive) come to school in a boring and sensory depressed education system. The way an education system can cater to these generation of digital natives is to speak their language. (Prensky, 2001).

One attempt to 'speak' the language of the new millennial generation is by engaging in e-Learning or Technology enhanced language learning/teaching. E-Learning is one of the useful platform which marries technology and education. When it is applied in a suitable condition, E-Learning is a beneficial tool for education for both students and teachers. This is even more so for the higher education system where E-Learning will boost Teacher-Students connectivity and provide a thorough learning experience.

One component which requires further discussion and investigation is the Digital Literacy which consists of many different aspects of skills. Encompassing IT skills, Digital Literacy also emphasizing on the ability for critical thinking (Gilster, 1997 in Calvani et.al, 2012). Van Deursen ((2010, in van Dijk, 2012) have managed to refined the digital/internet skills into six types.

$>$ Operational Skills: Actions required to operate a digital medium ("Button Knowledge)

$>$ Formal Skills: Handling the formal structures of the medium; here: browsing and navigating.

$>$ Information Skills: Searching, selecting and evaluating information in digital media, e.g. Search Engines

$>$ Communication Skills; mailing, contacting, creating online identities, draw attention and giving opinions. 
$>$ Content-Creation Skills: Make contributions to the internet with particular plan or design

$>$ Strategic skills; use the digital medium as a means to achieve particular professional and personal goals.

Every students who appears to be at ease in using their smartphones, laptops, tab and other gadgets are digital literate but to what extend and what level? How well are they coping with utilizing the immense benefit at their fingertip to aide their learning? How well can the lecturers or teacher employ incorporate these gadgets effectively in their teaching? Warschauer (2001) mentioned research result that when online learning activities are too highly restrictive and focus on form to the exclusion of content and exert high degree of teacher control, students may fail because it does not allow them to pursue their own initiatives and interest thus leads to frustration and demotivation. On the other hand, highly decentralized and diverse nature of online learning can be confusing and made students lose focus and teaching/learning process will not have achieved the intended goals.

FKIP (Faculty of Teacher's Training and Educational Sciences) of Pattimura University is gearing up to welcome the challenge of educating the digital natives by developing the faculty E-Learning system. In these past few years, E-Learning training has become a mandatory training for lecturers. In the light of this, English Department of FKIP-Unpatti is also working hard to join these new wave of educational endeavors. However, technology enhanced language teaching and learning or in particular E-Learning is still a very new method. Lecturers are actively using social media and emails to support their teaching and learning process but only one lecturer has been fully implementing E-Learning through Edmodo platform in the past 2 years in her classes. Recently, FKIP-Unpatti conducted a 2 days training for lecturers in how to operate the faculty's E-Learning system which use Moodle Platforms. The E-Learning system mentioned is sadly temporarily inaccessible at the time this paper is written. Despite, that the result of the workshop was the ready-to-use complete E-Learning sites with lessons, test banks, assignment, quiz, assessments etc.

This paper was inspired shortly after the workshop by the thoughts of how ready are the students to embrace E-Learning. Technically and theoretically, the E-Learning system is available in spite the glitch and technical errors. This is supported by facilities and infrastructure such as computers and internet connections that is now available and continue to be upgraded. E-Learning content such as syllabus and lessons are being developed and perfected. Therefore, many believe that we are ready to launch. This opinion is acceptable because there are 4 main components in launching E-Learning: Access, affordability, relevancy of content and skills (EDCL, 2009). And despite the setbacks, problems and shortcomings, FKIPUnpatti and English department in particular are ready for ELearning.

This paper would like to argue that the faculty, University and of course English department need to also invest heavily and strategically in the skills such as Digital Literacy and Readiness of both Lecturers and Students. EDCL Foundation's Digital Literacy Report 2009 emphasize that "many national and international policies and investments focus on addressing the first 3 components, often to the detriment of a structured focus on skills". This goes to say that availability of facility and infrastructure such as availability of internet access, affordability of technology gadgets cannot be used as an indicator of ability and skills in engaging in technology enhanced Language Learning such as E-Learning. This paper would like to argue that the component of readiness is crucial to support the successful application of E-Learning. Therefore, there needs to have a baseline data which will support the discussion and policy making. This paper would like to contribute in a smaller scale to the discussion.

\section{RESEARCH METHOD}

\section{A. Reseach Questions}

The research aims to answer an overarching question of how ready are the students of English Department, FKIP Unpatti to embark on E-Learning and Technology Enhanced Language Learning/Teaching.

Within it, there are 4 sub-questions to be answered:

1. What is the background of the students of English Department, FKIP-Unpatti?

2. What are their habit and preferences when they are online?

3. What resources are available and accessible to them?

4. What are the students perceived level of Digital Literacy Skill?

\section{B. Research Method and Instruments}

This is a qualitative research by using survey method. The survey is conducted through online questionnaire as the main instruments. The online questionnaire is created on GoogleDoc and links are given to students through class Social Media Group. Despite the fact that the research could have conducted pen and paper questionnaire which with the researcher's position as teaching and opportunities to use face-to-face class meeting to 'enforce' respondents to give feedback, this research choose the online questionnaire as a simulation for the 4 sub-questions.

There are 45 questions in the online questionnaire which are divided into 4 data categories: 1) Demographic Data, 2) Habit and Preferences, 3) Resources and 4) Perceived Level of Digital Literacy Skill.

The online questionnaire is designed to get information on

1. Students' demographic data which includes their backgrounds of life (Q 1,2,12,13,14,15 = 6 questions)

2. Students' habit and preferences (Q 3-11 = 9 questions)

3. Resources available to the students (Q $3,4,5,9,10,11,14,15=8$ questions)

4. Students' perceived level of Digital Literacy Skill. (part $2=30$ questions). 
The Part 2 of the questionnaire uses the Digital Literacy Checklist Questions by The Open University (Reedy and Goodfellow, 2012) which follows their Digital and Information Literacy Framework. The purpose of the application of this DIL checklist questions are "to provide a common reference point for module, program, and qualification terms to be used in determining markers of progression in digital literacy that can be integrated with other learning outcomes and student attributes" (The Open University, 2012). The questions are also aimed to measure the students "Perceived" level of Digital Literacy Skills because there are no question which specifically tested their DIL abilities.

The questionnaire are given to 3 batches of ED students: 2014 batch, 2015 batch and 2016 batch. These batches are chosen because they are the active students who are still in campus and to whom the E-Learning will be tried to.

\section{FINDINGS AND DISCUSSION}

There are a total of 63 respondents who completed the questionnaires. 17 respondents or $27 \%$ of the total 2016 batch, 20 respondents or $32 \%$ of the total 2015 batch and 24 respondents or $38 \%$ of the total 2014 batch. These were completed after 1 month of requests and periodic reminder to the students. Although these are not the number desired by the study to get significant results, the discussion will use these result as projection of the overall condition of the ED Students.

\section{A. Demographic Data of ED Students}

The questionnaire survey reveal the following facts:

1. 12 respondents $(19 \%)$ out of 63 respondents have their own desktop computer. Meanwhile 47 respondents $(77 \%)$ of the respondents out of 63 respondents have their own laptop.

2. All 63 respondents have their own Hand phone. However, 2 of the students admitted that their phone cannot be used for internet browsing and other activity that requires internet. "

3. $73 \%$ of the respondents use Telkomsel Internet Data. $27 \%$ uses IndieHome, $14.8 \%$ use Telkomsel Wi-Fi corner (one-off paid service), 21\% use Campus Wi-Fi, $29 \%$ use $\mathrm{Wi}-\mathrm{Fi}$ at café/restaurants/hang out places, $29 \%$ use Wi-Fi or internet connection at their friends house. Only $1 \%$ indication the use of other internet providers.

4. $43 \%$ of the respondents do different kind of part-times and volunteering jobs: $5 \%$ entrepreneurs, $2 \%$ Youth Ambassadors, 21\% part-time English teaching Assistants, 3\% hard labor, 8\% Volunteers, 2\% CGI freelance, $3 \%$ other jobs. This means, $57 \%$ of the respondents are not working and rely on financial resources from their parents.

5. Those with paid part-time jobs earned the salary in the range between IDR 50,000 - IDR 300,000. And these are only $29 \%$ of the total respondents.
6. $24.6 \%$ of the respondents' father are Government Officials, $16.4 \%$ are entrepreneur, $9.8 \%$ are farmers/fishermen while the rest are assortments of Clergyman, driver, ojek driver, passed away etc.

7. $50.8 \%$ of the respondents' mother are stay at home mothers, 23\% are Government Officials, 9.8\% are entrepreneur and the rest are assortments of different occupations.

\section{B. Students Habit and Preferences on ICT usage}

1. $36.1 \%$ admitted to go online every day in the afternoon and/or evening. $31.1 \%$ admitted to be online all day.

2. Google search dominates the online activity most commonly done by students when they go online at $91.8 \%$, followed by Facebook $(73.8 \%)$, Instagram (70.5\%), Line/WA (65.6\%), Email (50.8\%), ELearning/Online Learning (34.4\%) and Online Game (18\%)

3. $49.2 \%$ reported to spend between IDR 50,000,- -IDR $100,000,-$ per month, $8.2 \%$ spend between IDR $100,000-$-IDR 150,000 ,- per month, and $11.5 \%$ spend between IDR 150,000,--IDR 200,000,- per month.

4. Students' online/internet funds comes from their parents at $55.7 \%, 27.9 \%$ is self-funded, and the rest utilized free $\mathrm{Wi}-\mathrm{Fi}$ and internet connection whenever they can find one.

\section{Available Resources}

Currently internet/Wi-Fi connectivity is available at Campus B Unpatti where English Department residing. However, the connectivity is very poor that students would rather wait until after office hours to use the internet for their assignments. This means student's stay late at night on campus complex with scarce lighting.

Therefore, students often goes to Telkom main office which is close to Campus B and use their One-Off Paid Internet corner. Students will lugged all their books and laptops and notes. And sat on a long benches or plastic chairs on long communal tables to do their required work.

Telkomsel dominates the provider service with very high price. For comparison, as a lecturer I used to buy IDR 103,000,- for 2 Gigabytes size of 4G/3G Internet Data Plan. I use it for Facebook, Googling, reading internet content, edit and score my online classes, downloading new supporting materials to use in class. The data plan will lasted mostly for 23 days.

Current Faculty E-Learning system developed for use are on Moodle platforms. However, the system relies of overseas operator and administrator and over some problem the system as this paper is written is not functioning. The University ELearning system also uses Moodle platforms which currently are running with University's own administrator and operator. Nevertheless, the Moodle platforms in the writer personal view, is not the most user-friendly and attractive compared to other free E-Learning Platforms available in the web such as Edmodo, Canvas etc. 


\section{Students' Perceived Level of Digital Literacy}

There are 30 statements in the perceived Digital Literacy level Sections.it is divided into several skills sections: Understanding digital practices (Q 1-8), Finding information (Question 9-17), Using Information (Question 18-24) and Creating Information (Question 25-30). The result shows that

1. In the skill of understanding digital practices, majority of the answers strongly indicates that students are only "Quite confident" in their skills. Only one out of the 8 questions where almost the same percentage of respond (45.9\% and $44.5 \%)$ was given. Statement number 6 asks students about their confidence in using online tools and website to find and record information online. Their higher answer indicate "Very Confident"

2. In the skill of finding information, majority of the answers indicate "Quite Confident" level. There are 2 statements which get significantly higher percentage of "Very Confident" Indication which are question number 9 and 13. Question number 9 asks students on their knowledge of what information they can find on the web. 55.7\% indicates "Very Confident" and none admitting "Not Confidence". Question number 13 receive the most significant confident level at $63.9 \%$ when asked about using social network as a source of information.

3. In the skill of using information, all indications point toward "Quite Confident"

4. In the skill of creating information, students indicate tendency between "Quite Confident" to "Not Confident".

\section{E. Discussion}

The findings gave a rough picture of ED students were $84 \%$ own laptops and $98 \%$ owns a smartphones or phones with ability to connect to internet and other internet based tasks. Less than $50 \%$ of respondents hold a paid part-time job and rely their expenses on their parents who are government officials. These factors is worsen by the fact that commonly used internet provider still charge an immensely expensive cost for Internet data plan. The current situation of campus free Wi$\mathrm{Fi}$ or other accessible internet connection are still questionable from the point of view of accessibility and availability.

Students perceived level of digital literacy skills, indicates that they feel that they are quite confident in their digital literacy skills. This shows that students feel that they know enough but there are still room to improve.

The question remain to answer is whether these data will be able to answer whether English Department Students are ready for E-Learning and Technology Enhanced Language Learning/Teaching. This paper would like to argue that we are not quite ready yet. Despite the fact that students' perceived level of digital literacy indicates enough confidence, this needs to be further tested and confirmed.

Based on EDCL (2009) components of digital literacy access (Access, affordability, relevancy of content and skills). Then for sure we are still lacking on all components. On
Access, facilities and infrastructures to support the running of the system are somewhat available but not readily and massively accessible. On affordability, student's demographic background and the available resources do not walk hand-inhand as the accessible, reliable and available internet connection is still a luxury to most students. On relevancy of contents, E-Learning content development is still underway. Many lecturers are still on training on how to design lessons let alone harnessing their ability to operate and administer an ELearning system. Last, on skills, both lecturers and students have a long way to go. Not just on the skill to use the available system currently but also to combat anxiety/phobia or fear to use the computer for E-Learning.

A simple example is in the turnout of these online survey. Students have been given training on how to use/complete the survey, weekly reminder has been given, a door-prize for the lucky respondents has been issued and yet, the feedback are not as many as it is expected. Upon inquiring the students, they admitted 3 major reasons: 1) they do not have internet data (or money to buy it). 2) Internet connection at campus where they wanted to do it is very slow that they get impatient to do it thus decided to quit it, 3) they are very unsure of whether they will know how to do it.

\section{CONCLUSION AND FURTHER RECOMMENDATIONS}

After 2 years of applying E-Learning through various internet based platforms, the issue of readiness and digital literacy has become very important for me and for the department. It is imperative to have a ready, accessible and available system, content and infrastructures but the skills of the users, either lecturer or students must be put to the fore front too. Currently English Department still need to invest on developing the digital literacy and digital readiness of its students and lecturers.

In order to do that, there are several recommendations that can be put forward. These recommendations can by myself as a lecturer and as an academics or by the English Departments and/or faculty and university.

1. Conduct a concise research on digital literacy of both students and lecturers to have a much more correct and effective baseline data.

2. Upgrade the E-Learning Platforms, accessibility and operating system

3. Invest in continuous and periodic training for lecturers as content developer and E-Learning system administrator/operator and Digital Literacy

4. Invest also in continuous and periodic training for students as responsible, effective and efficient users

5. Provide accessible internet connection for students and lecturers

The 5 recommendations put forward in this paper hoped to assure that English Department will be able to be ready and immersed in the E-Learning and Technology Enhanced Language Learning/Teaching. 


\section{REFERENCES}

[1] Calvani, A., Cartelli, A, Fini, A., Ranieri, M. (2008). Models and Instruments for Assessing Digital Competence at School'. Journal of eLearning amd knowledge Society vol. 4, n. 3, September 2008.

[2] EDCL Foundation. (2009). Digital Literacy Report - 2009.

[3] Prensky, M. (2001). "Digital Natives, Digital Immigrants”. On the Horizon . (MCB) University Press, Vol. 9. No. 5, October 2001)

[4] Reedy, K and Goodfellow, R. (2012). Digital and Information Literacy Framework. The Open University.

[5] Robinson, K. (2006). Do Schools Kill Creativity? [TEDTalk Video]. Retrived from https://www.ted.com/talks/ken_robinson_says schools kill creativity ?language $=$ en

[6] The Open University. (2012). Being Digital: Digital Literacy Skills Checklist.

[7] Van Dijk, JAGM. (2012). The Evolution of the Digital Divide. Digital Enlightenment Yearbook. IOS Press.

[8] Warschauer, M. (2001). Online Comunication. The Cambridge Guide to Teaching English to Speaker of Other Languages. Cambridge:CUP 